Pacific Journal of Mathematics

SUMMABILITY OF SUBSEQUENCES AND STRETCHINGS OF 


\title{
SUMMABILITY OF SUBSEQUENCES AND STRETCHINGS OF SEQUENCES
}

\author{
DAVID F. DAWSON
}

\begin{abstract}
In 1943 R. C. Buck gave a summability characterization of real convergent sequences by showing that a real sequence $x$ is convergent if there exists a regular matrix summability method which sums every subsequence of $x$. In 1944 R. P. Agnew generalized Buck's result by showing that if $x$ is a bounded complex sequence and $A$ is a regular matrix, then there exists a subsequence $y$ of $x$ such that every limit point of $x$ is a limit point of $A y$. In the present paper a theorem concerning "stretchings" of sequences is proved; and from this theorem, summability characterizations of several classes of sequences are obtained, together with an extension of Agnew's result.
\end{abstract}

Definition. The sequence $y=\left\{y_{p}\right\}_{p=1}^{\infty}$ is a stretching of $x=\left\{x_{p}\right\}_{p=1}^{\infty}$ provided there exists an increasing sequence $\left\{m_{p}\right\}_{p=0}^{\infty}$ of integers such that $m_{0}=1$ and $y_{q}=x_{p}$ if $m_{p-1} \leqq q<m_{p}, p=1,2,3, \ldots$. Under these conditions, we shall say that $y$ is the stretching of $x$ induced by $\left\{m_{p}\right\}$.

Conditions which are necessary and sufficient for a matrix $A=$ $\left(a_{p q}\right)$ to be a regular summability method are

(1) $\left\{a_{p q}\right\}_{p=1}^{\infty}$ converges to $0, q=1,2,3, \cdots$,

(2) $\left\{\sum_{q=1}^{\infty} a_{p q}\right\}_{p=1}^{\infty}$ converges to 1 ,

(3) $\sup _{p} \sum_{q=1}^{\infty}\left|a_{p q}\right|<\infty$.

Let $\mathscr{P}$ denote the set of all matrices $P$ such that for all $x, P x$ is a subsequence of $x$, and let $Q$ denote the set of all matrices $Q$ such that for all $x, Q x$ is a stretching of $x$.

We note that any $P=\left(p_{i j}\right) \in \mathscr{P}$ is determined by an increasing sequence $\left\{n_{i}\right\}_{i=1}^{\infty}$ of positive integers as follows: $p_{i j}=1$ if $j=n_{i}, p_{i j}=$ 0 otherwise. Similarly, any $Q=\left(q_{i j}\right) \in \mathbb{Q}$ is determined by an increasing sequence $\left\{n_{i}\right\}_{i=0}^{\infty}, n_{0}=1$, of integers as follows: $q_{i j}=1$ if $n_{j-1} \leqq$ $i<n_{j}, q_{i j}=0$ otherwise.

Clearly all $P \in \mathscr{P}$ and $Q \in \mathscr{Q}$ are regular.

If $x$ is the sequence of partial sums of a series $\sum c_{p}$, then any subsequence of $x$ is the sequence of partial sums of a series obtained by bracketing the terms of $\sum c_{p}$ appropriately. On the other hand, any stretching of $x$ is the sequence of partial sums of a series obtained by inserting zero terms in $\sum c_{p}$ appropriately.

A series $\sum c_{p}$ with partial sums $\left\{x_{p}\right\}$ converges absolutely if and only if $\sum\left|x_{p}-x_{p+1}\right|<\infty$. Thus a sequence $\left\{t_{p}\right\}$ is said to converge absolutely (or to be of bounded variation) provided $\sum\left|t_{p}-t_{p+1}\right|<\infty$. 
We will let $B V$ denote the set of all complex sequences which converge absolutely. These sequences have the property that the sequence of real (imaginary) parts of the terms is the difference of convergent nondecreasing sequences.

In light of Buck's result [2], [3], one might conjecture that a real sequence $x \in B V$ if there exists a regular matrix $A$ such that $A y \in B V$ for every subsequence $y$ of $x$. This is not true, as shown by the following example. Let $x$ be a null sequence such that $x \notin B V$. Let $\left\{n_{q}\right\}_{q=1}^{\infty}$ be an increasing sequence of positive integers such that $\left|x_{p}\right|<2^{-q}$ if $p \geqq n_{q}$. Let $A=\left(a_{p q}\right)$ be defined by $a_{p q}=1$ if $q=n_{p}, a_{p q}=$ 0 otherwise. Clearly $A$ is regular and if $y$ is a subsequence of $x$, then $A y \in B V$. The conjecture is valid, however, if we replace "subsequence" with "stretching," as shown by Theorem 2 .

Note that (3) of the regularity conditions is not assumed in any of our results which follow.

THEOREM 1. If $x$ is a complex sequence, $A$ is a matrix satisfying (1) and (2) of the regularity conditions, and $\varepsilon$ is a positive term null sequence, then there exist $P \in \mathscr{P}$ and $Q \in \mathbb{Q}$ such that $P A Q x=x+u$, where $\left|u_{n}\right|<\varepsilon_{n}, n=1,2,3, \cdots$.

Proof. Let $w_{n}^{-1}=1+\left|x_{1}\right|+\cdots+\left|x_{n}\right|, n=1,2,3, \cdots$ Take $n_{1}$ and $m_{1}$ such that

$$
\left|\sum_{q=1}^{m_{1}-1} a_{n_{1} q}-1\right|<\varepsilon_{1} 2^{-2} w_{1},\left|\sum_{q=s}^{t} a_{n_{1} q}\right|<\varepsilon_{1} 2^{-3} w_{2}, m_{1} \leqq s \leqq t .
$$

Using (1), we can find a positive integer $N$ such that if $n>N$, then

$$
\sum_{q=1}^{m_{1}-1}\left|a_{n q}\right|<\varepsilon_{2} 2^{-2} w_{1}
$$

Take $n_{2}>n_{1}+N$ and $m_{2}>m_{1}$ such that

$$
\left|\sum_{q=m_{1}}^{m_{2}-1} a_{n_{2} q}-1\right|<\varepsilon_{2} 2^{-2} w_{2}
$$

and

$$
\left|\sum_{q=s}^{t} a_{n_{j} q}\right|<\varepsilon_{j} 2^{j-5} w_{3}, m_{2} \leqq s \leqq t, j=1,2 .
$$

Take $n_{3}>n_{2}$ and $m_{3}>m_{2}$ such that

$$
\begin{gathered}
\sum_{q=1}^{m_{2}-1}\left|a_{n_{3} q}\right|<\varepsilon_{3} 2^{-2} w_{2},\left|\sum_{q=m_{2}}^{m_{3}-1} a_{n_{3} q}-1\right|<\varepsilon_{3} 2^{-2} w_{3}, \\
\left|\sum_{q=s}^{t} a_{n_{j} q}\right|<\varepsilon_{j} 2^{j-6} w_{4}, m_{3} \leqq s \leqq t, j=1,2,3 .
\end{gathered}
$$


Continue the process. Let $y$ be the stretching of $x$ induced by $\left\{m_{p}\right\}_{p=0}^{\infty}$, where $m_{0}=1$. It is trivial to apply the Cauchy condition in order to show that $\sum_{q=1}^{\infty} a_{n_{r} q} y_{q}$ converges, $r=1,2,3, \cdots$, and we omit the proof. If $r$ is a positive integer, we have

$$
\begin{aligned}
\left|\sum_{q=1}^{\infty} a_{n_{r} q} y_{q}-x_{r}\right| \leqq & \left|\sum_{q=m_{r-1}}^{m_{r}-1} a_{n_{r} q} y_{q}-x_{r}\right|+w_{r-1}^{-1} \sum_{q=1}^{m_{r-1}-1}\left|a_{n_{r} q}\right| \\
& +\sum_{p=r}^{\infty}\left|\sum_{q=m_{p}}^{m_{p+1}-1} a_{n_{r} q} y_{q}\right| \\
\leqq & \left|x_{r}\right|\left|\sum_{q=m_{r-1}}^{m_{r}-1} a_{n_{r} q}-1\right|+w_{r-1}^{-1} \varepsilon_{r} 2^{-2} w_{r-1} \\
& +\sum_{p=r}^{\infty}\left|x_{p+1}\right|\left|\sum_{q=m_{p}}^{m_{p+1}-1} a_{n_{r} q}\right| \\
\leqq & \left|x_{r}\right| \varepsilon_{r} 2^{-2} w_{r}+\varepsilon_{r} 2^{-2}+\sum_{p=r}^{\infty}\left|x_{p+1}\right| \varepsilon_{r} 2^{r-3-p} w_{p+1} \\
< & \varepsilon_{r} .
\end{aligned}
$$

Thus if $P \in \mathscr{P}$ is determined by $\left\{n_{p}\right\}$ and $Q \in \mathbb{Q}$ is determined by $\left\{m_{p}\right\}$, then $P A Q x=x+u$, where $\left|u_{n}\right|<\varepsilon_{n}, n=1,2,3, \cdots$. This completes the proof.

THEOREM 2. A complex sequence $x$ is convergent (absolutely convergent) [bounded] \{divergent to $\infty$ \} if there exists a matrix $A$ satisfying (1) and (2) of the regularity conditions such that $A y$ is convergent (absolutely convergent) [bounded] \{divergent to $\infty$ \} for every stretching $y$ of $x$.

Proof. Take $\varepsilon_{p}=2^{-p}, p=1,2,3, \cdots$, and apply Theorem 1 to obtain $P \in \mathscr{P}$ and $Q \in \mathbb{Q}$ such that $P A Q x=x+u$, where $\left|u_{n}\right|<\varepsilon_{n}$, $n=1,2,3, \cdots$. If $A y$ converges for every stretching $y$ of $x$, then $A Q x$ converges and so $P A Q x$ converges since $P$ is regular. Thus $x=$ $P A Q x-u$ converges since $u$ converges. If $A y \in B V$ for every stretching $y$ of $x$, then $A Q x \in B V$ and so $P A Q x \in B V$ since $P$ is super regular, i.e., preserves absolute convergence. Hence $x=P A Q x-u \in B V$ since $u \in B V$. The statements involving boundedness and divergence to $\infty$ follow similarly. This completes the proof.

Next we use Theorem 1 to prove an extension of the result of Agnew [1] previously mentioned. Specifically, we obtain Agnew's conclusion (in a sense) after weakening his hypothesis in two ways. Besides dropping the assumption that $A$ satisfy (3) of the regularity conditions, we replace the boundedness of $x$ with the assumption that $x$ have a finite limit point. 
THEOREM 3. If $x$ is a complex sequence having a finite limit point and $A$ is a matrix satisfying (1) and (2) of the regularity conditions, then there exist $P_{1}, P_{2} \in \mathscr{P}$ such that every finite limit point of $x$ is a limit point of $P_{1} A P_{2} x$.

Proof. Following Agnew [1, p. 596], we use the separability of the complex plane to obtain an infinite sequence $u_{1}, u_{2}, u_{3}, \cdots$, such that each $u_{j}$ is a finite limit point of $x$ and every finite limit point of $x$ is either a term of $u_{1}, u_{2}, u_{3}, \cdots$ or a limit point of this sequence. Still following Agnew, we form the sequence

$$
u_{1} ; u_{1}, u_{2} ; u_{1}, u_{2}, u_{3} ; \cdots
$$

which is then relabeled $v_{1}, v_{2}, v_{3}, \cdots$. Let $A$ be a matrix satisfying (1) and (2), and let $\left\{\varepsilon_{p}\right\}$ be a positive term null sequence. Apply Theorem 1 to obtain an increasing sequence $\left\{n_{p}\right\}$ of positive integers and a stretching $z$ of $v$ such that

$$
\left|\sum_{q=1}^{\infty} a_{n_{p} q} z_{q}-v_{p}\right|<\varepsilon_{p}, p=1,2,3, \cdots
$$

Then every finite limit point of $x$ is a limit point of $\left\{(A z)_{n_{p}}\right\}_{p=1}^{\infty}$. Let $\left\{m_{p}\right\}_{p=0}^{\infty}$ be an increasing sequence of positive integers such that $z$ is the stretching of $v$ induced by $\left\{m_{p}\right\}$. If $p$ is a positive integer, then, since each of the sequences $\left\{a_{j q}\right\}_{j=1}^{\infty}, m_{p-1} \leqq q<m_{p}-1$, is convergent, there exists a number $L_{p}>1$ such that $\left|a_{s t}\right|<L_{p}, s \geqq 1, m_{p-1} \leqq t<$ $m_{p}-1$. We now construct a subsequence $y$ of $x$ as follows. Let $y_{1}$, $\cdots, y_{m_{1}-1}$ be a finite subsequence of $x$ such that

$$
\sum_{p=1}^{m_{1}-1}\left|y_{p}-v_{1}\right|<\left(2 L_{1}\right)^{-1}
$$

Let $y_{m_{1}}, \cdots, y_{m_{2}-1}$ be such that $y_{1}, \cdots, y_{m_{2}-1}$ is a finite subsequence of $x$ and

$$
\sum_{p=m_{1}}^{m_{2}-1}\left|y_{p}-v_{2}\right|<\left(2^{2} L_{2}\right)^{-1}
$$

Continue the process. Using the convergence of $\sum_{q=1}^{\infty} a_{n_{p}} z_{q}$ and the Cauchy condition, it is easy to show that $\sum_{q=1}^{\infty} a_{n_{p}} y_{q}$ converges, $p=$ $1,2,3, \cdots$. The details will not be given. Let $\lambda>0$. Take $k$ to be a positive integer such that $2^{-k}<\lambda$. Take $N$ so that if $n>N$, then $\left|a_{n q}\right|<\lambda, 1 \leqq q<m_{k}$. For $n_{p}>N$, we have 


$$
\begin{aligned}
\left|\sum_{q=1}^{\infty} a_{n_{p} q} y_{q}-v_{p}\right| \leqq & \left|\sum_{q=1}^{\infty} a_{n_{p} q} y_{q}-\sum_{q=1}^{\infty} a_{n_{p} q} z_{q}\right|+\left|\sum_{q=1}^{\infty} a_{n_{p} q} z_{q}-v_{p}\right| \\
\leqq & \sum_{j=1}^{k} \sum_{q=m_{j-1}}^{m_{j}-1}\left|a_{n_{p} q}\right|\left|y_{q}-v_{j}\right| \\
& +\sum_{j=k+1}^{\infty} \sum_{q=m_{j-1}}^{m_{j}-1}\left|a_{n_{p} q}\right|\left|y_{q}-v_{j}\right|+\varepsilon_{p} \\
& <\lambda \sum_{j=1}^{k} 2^{-j}+\sum_{k=k+1}^{\infty} L_{j}\left(2^{j} L_{j}\right)^{-1}+\varepsilon_{p} \\
& <\lambda+2^{-k}+\varepsilon_{p} \\
& <2 \lambda+\varepsilon_{p}
\end{aligned}
$$

Hence every finite limit point of $x$ is a limit point of $\left\{(A y)_{n_{p}}\right\}_{p=1}^{\infty}$. Clearly the conclusion follows.

Corollary. A complex sequence $x$ diverges to $\infty$ if there exists a matrix $A$ satisfying (1) and (2) of the regularity conditions such that Ay diverges to $\infty$ for every subsequence $y$ of $x$.

Proof. Suppose $A$ satisfies (1) and (2) and $A y$ diverges to $\infty$ for every subsequence $y$ of $x$, but $x$ has a bounded subsequence. Then $x$ has a finite limit point $P$, and by the theorem, there exists a subsequence $z$ of $x$ such that $P$ is a limit point of $A z$. But this is a contradiction. Thus $x$ cannot have a bounded subsequence. Hence $x$ diverges to $\infty$, and the proof is complete.

It is interesting to note that in Theorem 3 we cannot in general prove that every limit point of $x$ (finite or infinite) is a limit point of $\left\{(A y)_{n_{p}}\right\}_{p=1}^{\infty}$. For example, let $x=\{1,0,4,0,16,0, \cdots\}$ and let $A$ be defined by $a_{p q}=2^{p-q-1}$ if $q \geqq p, a_{p q}=0$ otherwise. Clearly, if a subsequence $y$ of $x$ contains at most a finite number of nonzero terms, then $(A y)_{n} \rightarrow 0$ as $n \rightarrow \infty$. But if $y$ contains infinitely many nonzero terms of $x$, then $\sum_{q=1}^{\infty} a_{p q} y_{q}$ diverges, $p=1,2,3, \cdots$.

On the other hand, we have the following modification of Theorem 3.

THEOREM 4. If $x$ is a complex sequence and $A$ is a row-finite matrix satisfying (1) and (2) of the regularity conditions, then there exists a subsequence $y$ of $x$ such that every limit point of $x$ (finite or infinite) is a limit point of $A y$.

The proof of Theorem 4 involves only minor changes in the proof of Theorem 3, and will be omitted.

CoRollary. A complex sequence $x$ is bounded if there exists a matrix $A$ satisfying (1) and (2) of the regularity conditions such that $A y$ is bounded for every subsequence $y$ of $x$. 
Proof. Suppose $A$ satisfies (1) and (2) and $A y$ is bounded for every subsequence $y$ of $x$, but $x$ is not bounded. Then $A$ is row-finite, for otherwise we could construct a subsequence $z$ of $x$ such that $A z$ is not defined. Thus by the theorem, there exists a subsequence $w$ of $x$ such that $\infty$ is a limit point of $A w$. But this is a contradiction. Hence $x$ is bounded.

\section{REFERENCES}

1. R. P. Agnew, Summability of subsequences, Bull. Amer. Math. Soc., 50 (1944), 596598.

2. R. C. Buck, A note on subsequences, Bull. Amer. Math. Soc., 49 (1943), 898-899.

3. - An addendum to "A note on subsequences," Proc. Amer. Math. Soc., 7(1956), $1074-1075$.

Recieved October 8, 1971 and in revised form December 7, 1971.

North Texas State University 


\section{PACIFIC JOURNAL OF MATHEMATICS}

\section{EDITORS}

\section{H. SAMELSON}

Stanford University

Stanford, California 94305

C. R. Новву

University of Washington Seattle, Washington 98105

\section{J. DuGundJI}

Department of Mathematics University of Southern California Los Angeles, California 90007

RICHARD ARENS

University of California Los Angeles, California 90024

\section{ASSOCIATE EDITORS}
E. F. BECKENBACH
B. H. NeumanN
F. WOLF
K. YoSHIDA

\section{SUPPORTING INSTITUTIONS}

\author{
UNIVERSITY OF BRITISH COLUMBIA \\ CALIFORNIA INSTITUTE OF TECHNOLOGY \\ UNIVERSITY OF CALIFORNIA \\ MONTANA STATE UNIVERSITY \\ UNIVERSITY OF NEVADA \\ NEW MEXICO STATE UNIVERSITY \\ OREGON STATE UNIVERSITY \\ UNIVERSITY OF OREGON \\ OSAKA UNIVERSITY
}

\author{
UNIVERSITY OF SOUTHERN CALIFORNIA \\ STANFORD UNIVERSITY \\ UNIVERSITY OF TOKYO \\ UNIVERSITY OF UTAH \\ WASHINGTON STATE UNIVERSITY \\ UNIVERSITY OF WASHINGTON \\ $*{ }^{*}$
AMERICAN MATHEMATICAL SOCIETY
NAVAL WEAPONS CENTER
}

The Supporting Institutions listed above contribute to the cost of publication of this Journal, but they are not owners or publishers and have no responsibility for its content or policies.

Mathematical papers intended for publication in the Pacific Journal of Mathematics should be in typed form or offset-reproduced, (not dittoed), double spaced with large margins. Underline Greek letters in red, German in green, and script in blue. The first paragraph or two must be capable of being used separately as a synopsis of the entire paper. The editorial "we" must not be used in the synopsis, and items of the bibliography should not be cited there unless absolutely necessary, in which case they must be identified by author and Journal, rather than by item number. Manuscripts, in duplicate if possible, may be sent to any one of the four editors. Please classify according to the scheme of Math. Rev. Index to Vol, 39. All other communications to the editors should be addressed to the managing editor, Richard Arens, University of California, Los Angeles, California, 90024.

50 reprints are provided free for each article; additional copies may be obtained at cost in multiples of 50 .

The Pacific Journal of Mathematics is issued monthly as of January 1966. Regular subscription rate: $\$ 48.00$ a year (6 Vols., 12 issues). Special rate: $\$ 24.00$ a year to individual members of supporting institutions.

Subscriptions, orders for back numbers, and changes of address should be sent to Pacific Journal of Mathematics, 103 Highland Boulevard, Berkeley, California, 94708.

PUBLISHED BY PACIFIC JOURNAL OF MATHEMATICS, A NON-PROFIT CORPORATION

Printed at Kokusai Bunken Insatsusha (International Academic Printing Co., Ltd.), 270, 3-chome Totsuka-cho, Shinjuku-ku, Tokyo 160, Japan. 


\section{Pacific Journal of Mathematics}

\section{Vol. 44, No. $2 \quad$ June, 1973}

Tsuyoshi Andô, Closed range theorems for convex sets and linear liftings . . . . . . 393

Richard David Bourgin, Conically bounded sets in Banach spaces . . . . . . . . . 411

Robert Jay Buck, Hausdorff dimensions for compact sets in $R^{n} \ldots \ldots \ldots \ldots \ldots \ldots . \ldots 421$

Henry Cheng, A constructive Riemann mapping theorem ................ 435

David Fleming Dawson, Summability of subsequences and stretchings of

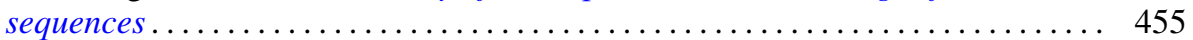

William Thomas Eaton, A two sided approximation theorem for 2-spheres ....... 461

Jay Paul Fillmore and John Herman Scheuneman, Fundamental groups of compact complete locally affine complex surfaces ....................... 487

Avner Friedman, Bounded entire solutions of elliptic equations . . . . . . . . . . . 497

Ronald Francis Gariepy, Multiplicity and the area of an $(n-1)$ continuous

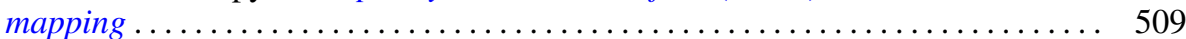

Andrew M. W. Glass, Archimedean extensions of directed interpolation groups . . . . 515

Morisuke Hasumi, Extreme points and unicity of extremum problems in $H^{1}$ on

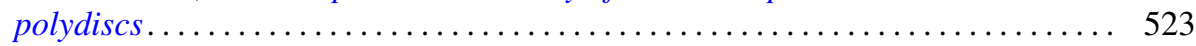

Trevor Ongley Hawkes, On the Fitting length of a soluble linear group . . . . . . 537

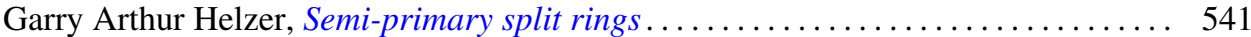

Melvin Hochster, Expanded radical ideals and semiregular ideals . . . . . . . . . 553

Keizō Kikuchi, Starlike and convex mappings in several complex variables . . . . . . 569

Charles Philip Lanski, On the relationship of a ring and the subring generated by its

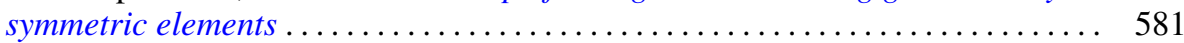

Jimmie Don Lawson, Intrinsic topologies in topological lattices and semilattices ........................................... 593

Roy Bruce Levow, Counterexamples to conjectures of Ryser and de Oliveira ...... 603

Arthur Larry Lieberman, Some representations of the automorphism group of an infinite continuous homogeneous measure algebra ..........

William George McArthur, $G_{\delta}$-diagonals and metrization theorems $\ldots .$.

James Murdoch McPherson, Wild arcs in three-space. II. An invariant of

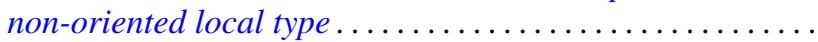

H. Millington and Maurice Sion, Inverse systems of group-valued measures ...

C. Edward Moore, Concrete semispaces and lexicographic separation of convex

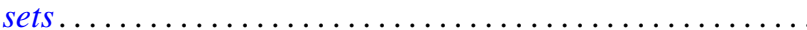

Jingyal Pak, Actions of torus $T^{n}$ on $(n+1)$-manifolds $M^{n+1}$.

Merrell Lee Patrick, Extensions of inequalities of the Laguerre and Turán type . . . . 675

Harold L. Peterson, Jr., Discontinuous characters and subgroups of finite index. . . . 683

S. P. Philipp, Abel summability of conjugate integrals . . . . . . . . . . . . . 693

R. B. Quintana and Charles R. B. Wright, On groups of exponent four satisfying an

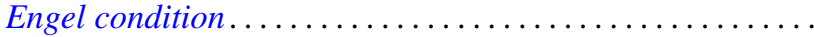

Marlon C. Rayburn, On Hausdorff compactifications. . . . . . . . . .

Martin G. Ribe, Necessary convexity conditions for the Hahn-Banach theorem in

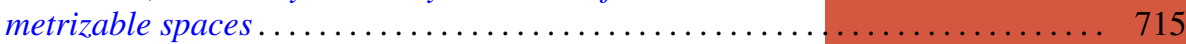

Ryōtarō Satō, On decomposition of transformations in infinite measure spaces .... 733

Peter Drummond Taylor, Subgradients of a convex function obtained from a

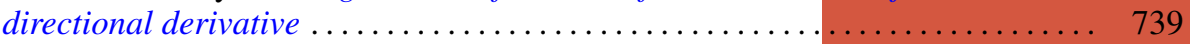

James William Thomas, A bifurcation theorem for $k$-set contractions . . . . . . . . 749 Clifford Edward Weil, A topological lemma and applications to real functions . . . . 757

Stephen Andrew Williams, A nonlinear elliptic boundary value problem . . ....... 767

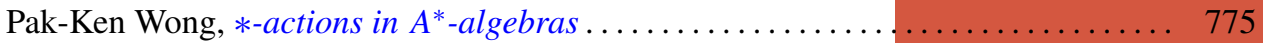

